\title{
BMJ Open Quality Quality improvement of intravenous to oral medication conversion using Lean Six Sigma methodologies
}

\author{
Julie Downen, ${ }^{1}$ Cassie Jaeger (1) ${ }^{2}$
}

To cite: Downen J, Jaeger C. Quality improvement of intravenous to oral medication conversion using Lean Six Sigma methodologies. BMJ Open Quality 2020;9:e000804. doi:10.1136/ bmjoq-2019-000804

- Additional material is published online only. To view please visit the journal online (http://dx.doi.org/10.1136/ bmjoq-2019-000804)

Received 19 August 2019 Revised 19 December 2019 Accepted 30 December 2019

Check for updates

(C) Author(s) (or their employer(s)) 2020. Re-use permitted under CC BY-NC. No commercial re-use. See rights and permissions. Published by BMJ.

${ }^{1}$ Pharmacy, Memorial Medical Center, Springfield, Illinois, USA ${ }^{2}$ Operations Improvement, Memorial Medical Center, Springfield, Illinois, USA

Correspondence to Dr Cassie Jaeger; Hawk.Cassie@mhsil.com

\begin{abstract}
Introduction Lack of medication conversion from intravenous to oral contributes to increased risk of infection, delayed discharges and higher medication costs. At our institution, intravenous to oral medication conversion rate was $76 \%$ with missed opportunity for conversion of $37 \%$. The goal of the project was to reduce the percent of missed opportunities for intravenous to oral conversion for applicable medications.

Methods A pharmacy-driven intravenous to oral policy and procedure was implemented. To identify potential opportunities, a patient worklist of applicable intravenous to oral medications was created for pharmacy review in real time. An intravenous to oral conversion order was implemented in the computerised provider order entry. 'Convert to oral' was added as an option in the electronic medication request and highlighted reminders were added to the electronic medication administration record for eligible medications.

Results After improvements, the missed opportunity rate for intravenous to oral conversion decreased from $37 \%(19 / 51)$ to $21 \%(24 / 113)(p=0.04$, two-proportion test), a $43 \%$ improvement. The trend in intravenous to oral conversion rate increased from $76 \%(39 / 51)$ to $85 \%(171 / 201)$ and severity adjusted length of stay was reduced from 8.1 days to 6.4 days post improvements $(p<0.001$, t-test).
\end{abstract}

\section{INTRODUCTION}

In an urban tertiary care 500 bed hospital in Illinois, USA, an opportunity was identified through a discharge optimisation project that patients were being treated with intravenous medications on the day of hospital discharge. The Infectious Diseases Society of America has identified intravenous to "per os', by mouth, medication conversion as an optimisation strategy to reduce length of stay and costs. ${ }^{1}$ On further review of a sample of patients on intravenous medications during fiscal year 2016, it was identified that intravenous to oral conversion was missed $37 \%$ $(19 / 51)$ of the time.

There are several intravenous to oral conversion misconceptions that delay or prohibit conversion including belief that oral antimicrobials are not equivalent to intravenous therapy. 'Literature has shown that oral therapy is efficacious, convenient, costeffective and safe.' ${ }^{2}$ Some practitioners feel that the same medication should be given orally that is being administered intravenous. However, there are a number of intravenous medications that do not have an oral formulation. Even though there may not be a direct conversion, there are often oral medications that have similar spectrum of activity that are just as effective as the intravenous equivalent. ${ }^{2}$ Lastly, there is the concept that Medicare reimbursement will be impacted if patients are on oral therapy while in the hospital. Using intravenous antimicrobial therapy as a justification for hospitalisations should not be done. As other medical issues are resolved and the patient is ready for discharge, conversion to oral therapy should help expedite the discharge process. ${ }^{2}$

A retrospective observational study by Tejaswini et al found that two-thirds of eligible patients were not switched from intravenous to oral medications. ${ }^{3}$ Mok et al reported that $35 \%$ of patients were eligible for intravenous to oral conversion and the average number of delayed or missed days for patients eligible for oral medication was 2.76 days with an estimated US\$789000 in potential cost savings per year. ${ }^{4}$ Hospitals have addressed this gap by implementing guidelines and computerised alerts. Chandrasekhar and PokkaVayalil reported that the percent of converted medications significantly increased from $6 \%$ to $72 \%$ after development and implementation of institutional intravenous to oral conversion guidelines. ${ }^{5}$ At another institution, addition of an intravenous to oral conversion form in charts of all patients who met conversion criteria increased the use of oral fluoroquinolones from $60.6 \%$ to $65.3 \%$. When the form was used in eligible patients, intravenous duration decreased by $42 \%$, although the study's sample size was small. ${ }^{6}$ Sze and Kong reported that the average time on intravenous antibiotics and length of stay was decreased when a form with intravenous 
to oral conversion criteria and recommended oral equivalents was attached to medical notes, compared with patients whose providers were contacted by clinical pharmacists to discuss potential conversions. The form required prescribers to accept the medication change or state reasons to reject the recommendation. ${ }^{7}$

Other studies have used computerised reminders and reports based on electronic dietary orders to improve conversion rates. Teich et al implemented a daily report that alerted pharmacists of patients receiving eligible intravenous medications who also had orders for an oral diet or other oral medications. Pharmacy reviewed eligible patients and made recommendations to the providers. Physicians agreed to convert the patient's medication from intravenous to oral $32 \%$ of the time. ${ }^{8}$ In another study, the cost of levofloxacin therapy was reduced by implementation of a computerised report identifying patients on intravenous levofloxacin receiving an oral diet or other oral medications. Pharmacists used the report to identify patients and encourage intravenous to oral switching. ${ }^{9}$

Our hospital uses Lean Six Sigma define, measure, analyse, improve, control (DMAIC) methodology for continuous improvement. Six Sigma methodology focuses on decreasing defect rates and variation, and Lean principles focus on eliminating waste and non-value added steps to influence quality and reliability. Although initially implemented in manufacturing, General Electric and Toyota, the use of Lean Six Sigma tools can effectively be used in service industries, including healthcare. ${ }^{10-15}$ The Lean Six Sigma approach is embedded within the organisation, with nearly $50 \%$ of the workforce exposed to some level of Lean Six Sigma training. Intravenous to oral conversion rate improvement was prioritised as project work by leadership in the organisation due to executive sponsor support, unknown root cause and solution, alignment with goals, expected benefits, and potential financial impact.

The purpose of this study was to decrease the rate of missed intravenous to oral conversion opportunities for eligible patients which aligns with our strategic plan for quality improvement of resource utilisation and reducing delays.

\section{METHODS}

This project was reviewed by the local institutional review board. It was determined that this project was not research involving human subjects, Reference: 016341. A multidisciplinary team comprised a hospitalist physician, family medicine resident, nursing outcomes improvement facilitator who was recently a floor nurse, two staff pharmacists, a pharmacy clinical coordinator and the director of pharmacy led the project. A representative from Information Technology was invited onto the team during the improve phase to help with electronic solutions. The project was supported by the Chief Nursing Officer and Chief Medical Officer. Stakeholders in this process included clinical staff, patient care facilitators, patients and the organisation. During the define phase, the team described the problem and inclusion and exclusion criteria. While there are many oral alternatives to intravenous medications, some of the conversions can be rather complex and cumbersome.

Thus, the initial scope of medications included:

- Antimicrobials: azithromycin, ciprofloxacin, clindamycin, doxycycline, levofloxacin, linezolid, metronidazole, moxifloxacin, fluconazole.

- Anticonvulsants: divalproex sodium, phenytoin, fosphenytoin, lacosamide, levetiracetam, valproic acid.

- Levothyroxine.

- $\mathrm{H}_{2}$ antagonists: famotidine, ranitidine.

- Pantoprazole.

In the measure phase, the current intravenous to oral process was reviewed and a process map was developed. The process map identified that different processes existed for each specialty, depending on who initiated the oral conversion (online supplementary figures 1-3). It was also identified that no one owned this process, thus it was not always deemed high priority. Key issues identified during process mapping included (1) re-evaluation of diet orders, diet tolerance and opportunity for conversion occurring at different points in the process for physicians, nurses and pharmacy, (2) there was a lack of notifications or triggers identifying candidates for oral conversion and (3) the process was cumbersome, depending on who was completing the conversion. For physicians, the electronic health record (EHR) required multiple orders to make the conversion while the process for pharmacy or nursing required a page to the physician to get orders for the process to occur.

In the analyse phase, a fishbone diagram was created to identify root causes for the missed intravenous to oral conversions. This tool organised potential issues into categories including diet orders, time constraints, workflow and discharge. Lack of a trigger for notification of diet changes, duration of time for nurses and physicians to place orders, oral recommendations made at the time of discharge and competing priorities were identified as potential causes for delay.

In the improve phase, based on these key root causes, interventions were identified through brainstorming and completion of an Impact to Effort Matrix that compared the feasibility of potential improvements. Potential solutions included alerting physicians and pharmacists of nothing by mouth (NPO) to oral diet changes, electronic triggers and worklists, an intravenous to oral order to pharmacy via computerised provider order entry (CPOE) and others (online supplementary figure 4). A control plan was developed and implemented as part of the control phase.

\section{Pharmacy-driven policy}

A pharmacy-driven intravenous to oral policy was implemented, which included criteria for medication 
Table 1 Intravenous to oral medication conversion and criteria

\begin{tabular}{|c|c|c|c|}
\hline Drug & Intravenous dose & Oral dose & Medication-specific criteria \\
\hline \multicolumn{4}{|l|}{ Anti-infectives* } \\
\hline Azithromycin & 250 mg-500 mg q24 hours & Same dose and frequency & \\
\hline Doxycycline & $100 \mathrm{mg}$ q12 hours & Same dose and frequency & \\
\hline Fluconazole & 100 mg-400 mg q24 hours & Same dose and frequency & \\
\hline Levofloxacin & 250-750 mg any frequency & Same dose and frequency & $\begin{array}{l}\text { Exclude patients receiving tube feeds } \\
\text { from conversion. }\end{array}$ \\
\hline Moxifloxacin & $400 \mathrm{mg}$ & Same dose and frequency & $\begin{array}{l}\text { Exclude patients receiving tube feeds } \\
\text { conversion. }\end{array}$ \\
\hline
\end{tabular}

\begin{tabular}{|c|c|c|c|}
\hline \multicolumn{4}{|l|}{ Anticonvulsants $†$} \\
\hline Fosphenytoin & Scheduled regimen & $\begin{array}{l}\text { Phenytoin: Total daily dose } \\
\text { of fosphenytoin divided three } \\
\text { times per day }\end{array}$ & $\begin{array}{l}\text { Exclude patients receiving tube feeds } \\
\text { from conversion. }\end{array}$ \\
\hline Lacosamide & $50 \mathrm{mg}-200 \mathrm{mg}$ q12 hours & Same dose and frequency & \\
\hline Levetiracetam & $\begin{array}{l}500 \mathrm{mg}-1500 \mathrm{mg} \text { intravenous } \\
\text { two times per day }\end{array}$ & Same dose and frequency & \\
\hline \multicolumn{4}{|l|}{$\mathrm{H}_{2} \mathrm{RA}$} \\
\hline Famotidine & $20-40 \mathrm{mg}$ & Same dose and frequency & \\
\hline Ranitidine & 50 mg q6-q8hours & $150 \mathrm{mg}$ two times per day & \\
\hline Pantoprazole & $40 \mathrm{mg}$ & $\begin{array}{l}\text { Pantoprazole: Same dose } \\
\text { and frequency } \\
\text { Lansoprazole Solu-Tab: } \\
30 \text { mg same frequency }\end{array}$ & \\
\hline
\end{tabular}

${ }^{*}$ Remember anti-infective specific cAnti-infective Specific Criteria.

†Remember anticonvulsant specific exclusion c Anticonvulsant Specific Exclusion Criteria.

$\mathrm{H}_{2} \mathrm{RA}, \mathrm{H}_{2}$ receptor antagonist; q, every.

conversion, both inclusion and exclusion, as well as a table specifying how to make the conversion (table 1). Medication or class-specific criteria were implemented to ensure safe conversion of medications. Physicians wanted to be part of the process but not own the process and were supportive of a pharmacy-driven intravenous to oral policy. The team reviewed current practice and other protocols to determine the best option for standardisation and execution. Medications that were chosen had standard conversions or oral equivalents, increasing physician and leader willingness to implement. For example, pantoprazole has the same dose and frequency 


\section{Clinical Pharmacist Worklist}
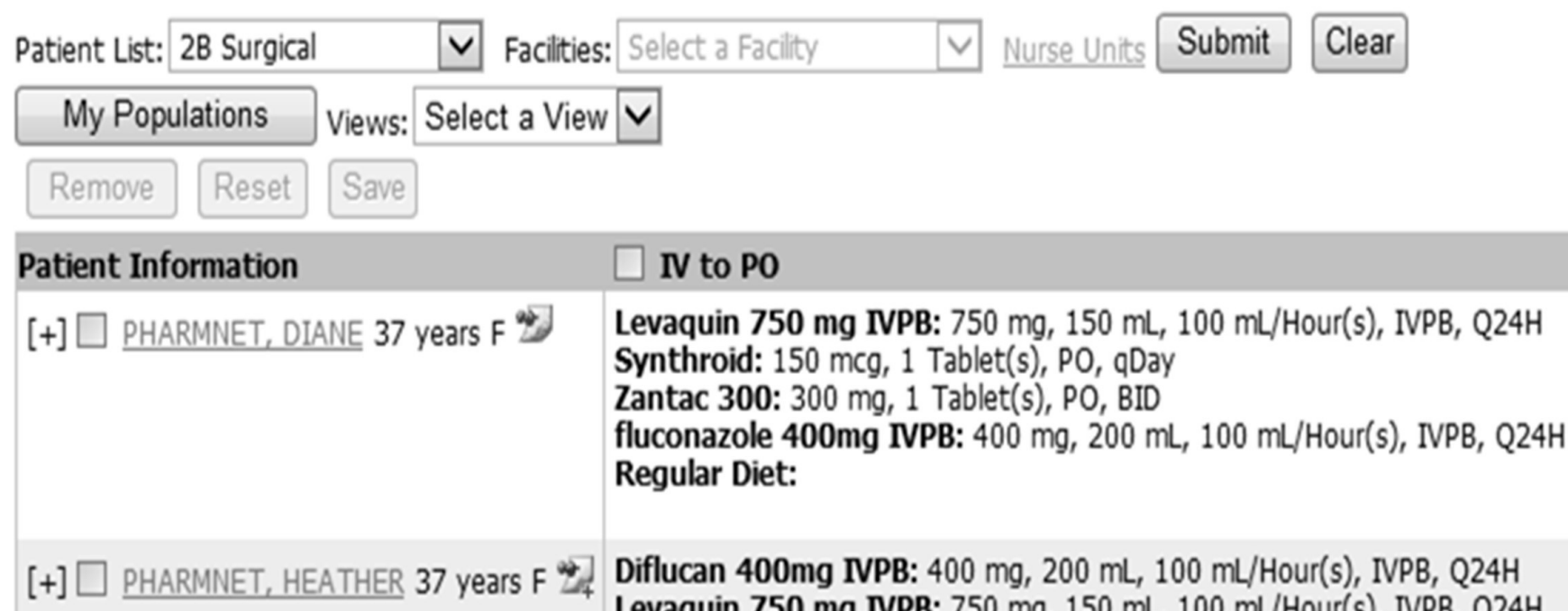

Diflucan 400mg IVPB: $400 \mathrm{mg}, 200 \mathrm{~mL}, 100 \mathrm{~mL} /$ Hour(s), IVPB, Q24H Levaquin $750 \mathrm{mg}$ IVPB: $750 \mathrm{mg}, 150 \mathrm{~mL}, 100 \mathrm{~mL} /$ Hour(s), IVPB, Q24H Zyvox $600 \mathrm{mg}$ IVPB: $600 \mathrm{mg}, 300 \mathrm{~mL}, 300 \mathrm{~mL} /$ Hour(s), IVPB, Q12H levothyroxine oral: $150 \mu \mathrm{g}, 1$ Tablet(s), PO, qDay Cardiac Diet:

Figure 1 Screenshot of the Clinical Pharmacist Worklist of applicable intravenous (IV) to oral (PO) medications used to identify potential opportunities for conversion in real time. BID, two times per day; IVPB, intravenous piggyback; Q, every.

when given intravenous or by mouth. The team included dose, frequency and any medication-specific criteria in the table so that key information was listed in a single location.

\section{Clinical Pharmacist Worklist}

A Clinical Pharmacist Worklist was implemented (figure 1). This tool, an available feature in the EHR, allowed pharmacists the ability to identify patients in real time, as diet orders advanced. The worklist only identified patients who were on intravenous formulations of the medications that were included in the intravenous to oral policy. It is dynamic, so once the medications that were included in the policy were all oral or if a patient's diet order went back to NPO, the patient would no longer populate to the list. In addition, the list is customisable and can be updated when needed, for example, if additional medications are added to the policy.

Before initiation of this project, the pharmacist intravenous to oral worklist was a paper report that was outdated in practice. Pharmacy had been interested in using a dynamic worklist that would help streamline pharmacy's process and improve efficiency. Due to their interest in utilisation of an electronic worklist, pharmacy was open to the change. The worklist decreased the number of patients that pharmacy was reviewing due to diet information that was built into the report.

\section{Reminders added to EMR}

Comments were added to the electronic medication administration record (EMar) indicating which medications were part of the intravenous to oral policy (online supplementary figure 5A). These comments helped serve as another prompt or reminder to nursing staff for which medications were eligible for intravenous to oral conversion automatically by pharmacy.

\section{Addition of medication request feature}

In conjunction with EMar comments, a communication tool used by nursing staff to submit requests was updated. Nursing is now able to send communications to pharmacy using the medication request feature in the EMar. As part of this project, a 'Convert to oral' reason was added (online supplementary figure 5B). That way, if a nurse knows their patient is a candidate for oral conversion, such as taking other oral medications and is on an oral diet, this communication tool can be used to notify pharmacy. After notification, pharmacists would initiate the review process using the intravenous to oral policy criteria and convert, if appropriate. 'Convert to oral' was also added in the CPOE. This allowed physicians to be part of the process but not own the actual intravenous to oral conversion.

\section{Education}

Education was completed for the various clinical groups impacted by the changes. To educate nurses across 17 inpatient units, practice change was communicated electronically, pharmacists rounded on individual units and attended unit-based council meetings to share the changes and answer questions. Pharmacy presented at the monthly patient care facilitator meeting and hospitalists 


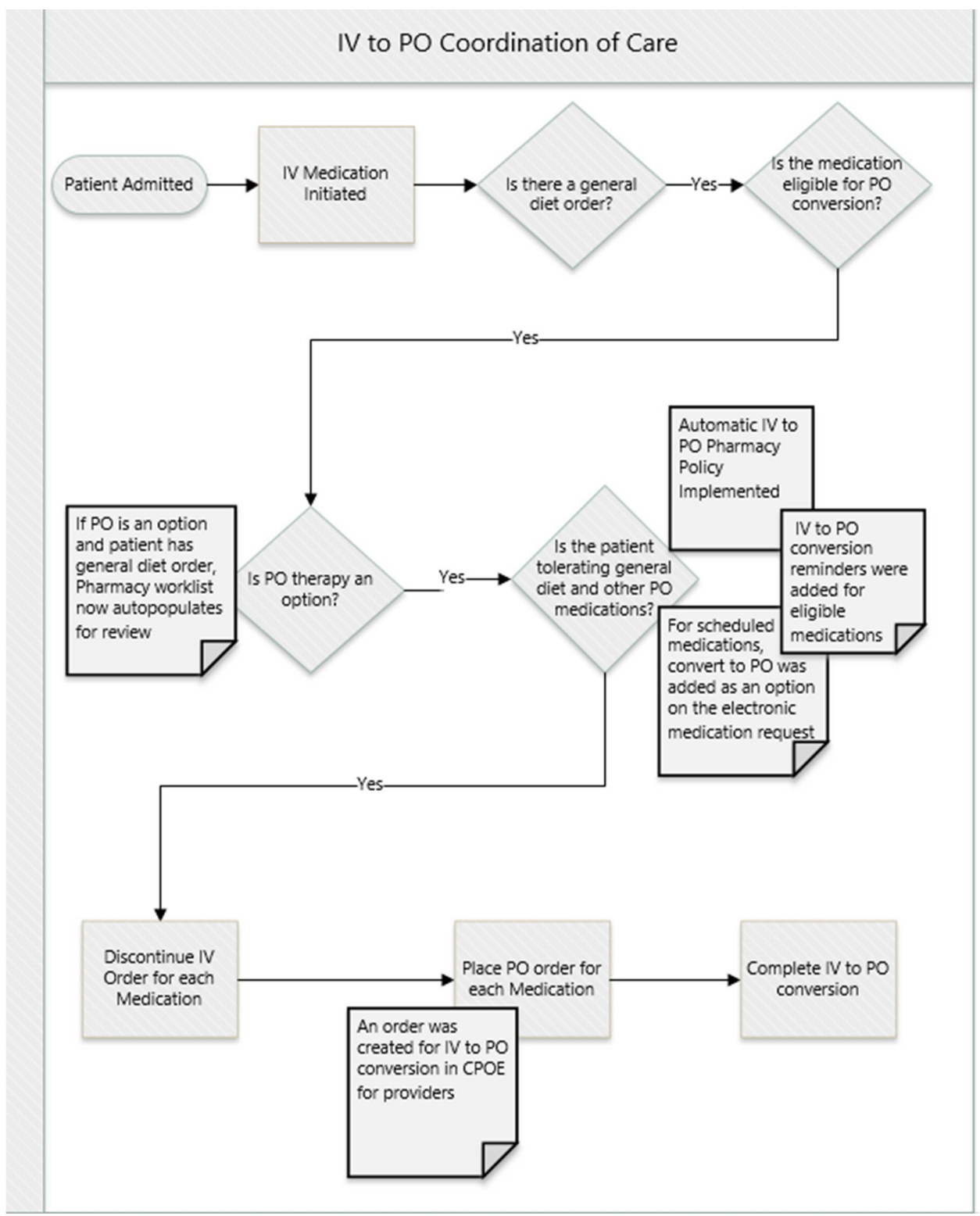

Figure 2 Process map of intravenous (IV) to by mouth (PO) coordination of care. Before implementation of process changes, diet orders, diet tolerance and opportunity for oral conversion were re-evaluated at different points in the process by physicians, nurses and pharmacy. Due to lack of notifications or triggers, staff were often unaware of diet order changes and eligible medications. Before the automatic intravenous to oral policy, pharmacy had to page the provider or wait until rounding was completed to make the conversion. CPOE, computerised provider order entry.

meeting. Changes were also shared at the adult inpatient internal medicine meeting, posted in the physician lounge, and communicated via Med Feed and the physician portal. The chair of the Pharmacy and Therapeutics committee was on the project team and facilitated physician notification and buy-in. Pharmacists were notified through email communications and staff meetings.

Interventions were implemented at various points in the process to address coordination of care (figure 2). Intravenous to oral missed opportunity rate and intravenous to oral conversion rate pre intervention and post intervention were analysed by two-proportion test. A missed opportunity for conversion is defined as either missing the conversion altogether or a conversion that could have been completed at an earlier time. Severity adjusted length of stay was analysed by two-tailed t-test. Statistics were performed in Minitab Statistical Software V.18.1. A p-value of $<0.05$ was considered significant.

\section{RESULTS}

The rate of missed opportunities declined from 37\% $(19 / 51)$ to $21 \%(24 / 113)$ resulting in a $43 \%$ improvement (two-proportion test, $\mathrm{p}=0.04$ ) (figure 3 ). The intravenous to oral conversion rate trend improved from $76 \%$ $(39 / 51)$ to $85 \%(171 / 201)$ post intervention (figure 4$)$ (two-proportion test, $\mathrm{p}=0.1$ ). Severity adjusted length 
Missed Opportunity Rate for IV to PO Conversion $100 \%$

$75 \%$

蒙 $50 \%$

$25 \%$

$0 \%$

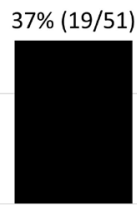

Pre-Intervention

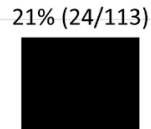

Post-Intervention

Figure 3 Rate of missed intravenous (IV) to by mouth (PO) opportunities was significantly reduced from $37 \%(19 / 51)$ to $21 \%(24 / 113)$ after implementation of an intravenous to oral policy, specific conversion criteria, a Clinical Pharmacist Worklist, an additional medication request option for nurses to communicate with pharmacy and reminders in the electronic medication administration record (two-proportion test, $\mathrm{p}=0.04$ ).

of stay was decreased from 8.1 days to 6.4 days (t-test, $\mathrm{p}<0.001)$.

\section{DISCUSSION}

Changes were implemented across 17 inpatient units for five different drug classes. Care teams were able to more easily identify opportunities, communicate medication conversion needs though a streamlined process and facilitate care coordination in a timely manner. Before the changes, staff felt it was difficult to request conversions and time was wasted in executing requests. Integration of reminders and the option to 'convert to oral' redesigned cultural views and workflow.

Chandrasekhar and PokkaVayalil increased the rate of converted medications from $6 \%$ to $72 \%$ after development and implementation of institutional intravenous to oral conversion guidelines. ${ }^{5}$ At another institution, addition of an intravenous to oral conversion form increased the use of oral medication from $60.6 \%$ to $65.3 \% .{ }^{6}$ In this study, implementation of an intravenous to oral policy, specific conversion criteria, a clinical pharmacist worklist, an additional medication request option for nurses to communicate with pharmacy and reminders in the EMar increased the trend in intravenous to oral conversion rate from $76 \%$ to $85 \% 6$ months post intervention, higher than the rates described.

Lau et al reported that the percent of doses of pantoprazole, a costly intravenous medication with an oral equivalent, administered when an oral equivalent was appropriate was $66 \%$, an estimated US $\$ 680$ of potential cost savings/patient for the medication alone, based on medication costs in the 2011 Red Book Average Wholesale Pricing. This study validates the potential cost savings for intravenous medications with an oral equivalent, in general and specifically pantoprazole, which was one of the medications included in this project. ${ }^{16}$ Total variable costs were decreased by US $\$ 220$ per patient resulting in US\$894000 annualised savings for the organisation for the pilot medications.

\section{LESSONS AND LIMITATIONS}

Lean Six Sigma projects require a control plan be developed as part of the control phase to ensure results are sustained over time. Measures and data collection plans were clearly outlined, review frequency action plans were created and target goals and special cause response steps were defined. Targets include intravenous to oral conversion rates $\geq 80 \%$, missed opportunity rates $\leq 20 \%$

\section{IV to PO Conversion Rate}

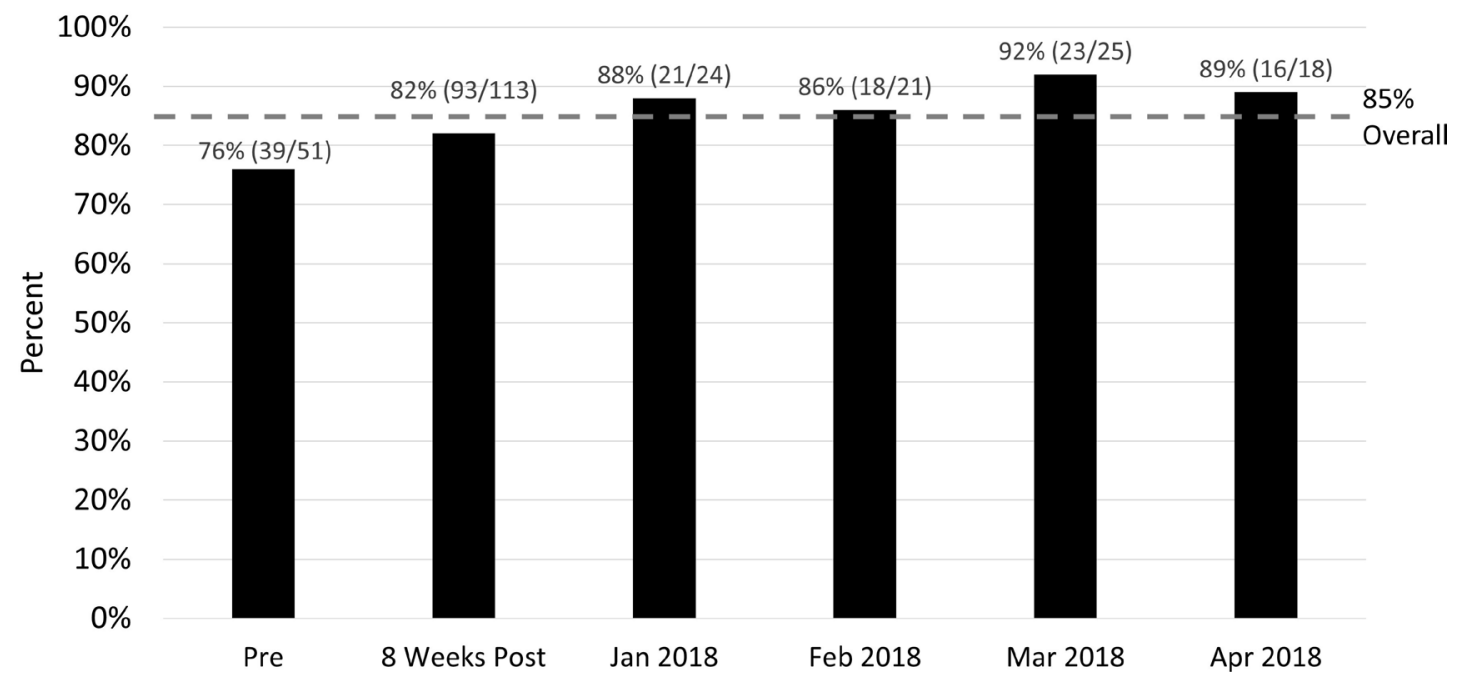

Figure 4 Intravenous (IV) to by mouth (PO) conversion rate increased from $76 \%$ to $85 \%$ post interventions ( $p=0.1$, twoproportion test). Improvement has been sustained at an average $85 \%$. 
and intravenous to oral criteria compliance at $100 \%$. The control plan was communicated via the project team to promote sustainability and further support the process owner. Process sustainability has been achieved by monthly audits of conversion rates, missed conversion rates and compliance with the intravenous to oral policy criteria. Ongoing evaluation and monitoring parameters are enforced to ensure improvements are sustained.

In a culture familiar with Lean Six Sigma, staff were open to proposed changes. Change management strategies included creating urgency, senior leadership support, team composition of front-line staff, simplified training and communication, and leveraging formal changes through policy. Changes were communicated to physicians at various department meetings and to registered nurses at unit-based councils. Lack of formal evaluation of the educational approach is a potential limitation of the study. As with any new process, there was an adjustment period while pharmacy incorporated tasks into their daily activities. As well, it appeared to be more challenging to convert antibiotics in some specialties. It was difficult to determine which medications to include in the initial scope of the project. The team wanted to include more complex medications but decided that a smaller scope would be more effective. Intravenous to oral missed opportunity rate and intravenous to oral conversion rate were collected by manual chart review, which was time consuming for pharmacy who maintained dayto-day operational duties. Since the initial go-live, several additional medications have been added including ampicillin-sulbactam (which is converted to amoxicillin-clavulanate), digoxin, folic acid, metoclopramide, orphenadnine, multivitamins, ondansetron, thiamine and voriconazole. Due to the high volume of patients on ondansetron that met criteria for the clinical pharmacist worklist and resistance to converting to an oral medication while the patient was feeling nauseous, ondansetron and metoclopramide were later excluded. The medication list continues to evolve over time, as needed.

\section{CONCLUSION}

After implementation of pharmacy-driven intravenous to oral policy, specific conversion criteria, a clinical pharmacist worklist, an additional medication request option to communicate with pharmacy and reminders in the EMar, the rate of missed opportunities for intravenous to oral conversion was significantly decreased. Processes are being spread to all affiliates in the health system via a Lean Six Sigma rollout plan embedded in the control phase. Additional project extensions include addition of intravenous medications with oral equivalents.

Acknowledgements The authors acknowledge the following: Megan Metzke, PharmD, BCPS, BCCCP; Megan Allen, PharmD, BCPS; Rachel Daniel, RN, Mark
Weaver, MD; Waiz Wasey, MD; Heather Strawn, PharmD; and Alisa Groesch, PharmD.

Contributors JD contributed to the study concept and design, acquisition of data, analysis of data, drafting of the manuscript and study supervision. CJ contributed to analysis of data, drafting of the manuscript and critical revision of the manuscript.

Funding The authors have not declared a specific grant for this research from any funding agency in the public, commercial or not-for-profit sectors.

Competing interests None declared.

Patient consent for publication Not required.

Provenance and peer review Not commissioned; externally peer reviewed.

Data availability statement No data are available.

Open access This is an open access article distributed in accordance with the Creative Commons Attribution Non Commercial (CC BY-NC 4.0) license, which permits others to distribute, remix, adapt, build upon this work non-commercially, and license their derivative works on different terms, provided the original work is properly cited, appropriate credit is given, any changes made indicated, and the use is non-commercial. See: http://creativecommons.org/licenses/by-nc/4.0/.

ORCID iD

Cassie Jaeger http://orcid.org/0000-0002-2726-6867

\section{REFERENCES}

1 Barlam TF, Cosgrove SE, Abbo LM, et al. Implementing an antibiotic stewardship program: guidelines by the infectious diseases Society of America and the Society for healthcare epidemiology of America. Clin Infect Dis 2016;62:e51-77.

2 Kuper KM. Intravenous to oral therapy conversion. In: Competence assessment tools for health-system pharmacies. 4th edn. ASHP, 2008: 347-60.

3 Tejaswini Y, Challa S, Nalla K, et al. Practice of intravenous to oral conversion of antibiotics and its influence on length of stay at a tertiary care Hospital: a prospective study. J Clin Diag Res 2018;12:FC01-4.

4 Mok M, Kinkade A, Tung A, et al. Identification of patients eligible for IV-to-PO conversion: a cost-minimization study. Can J Hosp Pharm 2016;69:301-5.

5 Chandrasekhar D, PokkaVayalil V. Cost minimization analysis on IV to oral conversion of antimicrobial agent by the clinical pharmacist intervention. Clin Epidemiol Glob Health 2019;7:60-5.

6 Thompson C, Zahradnik M, Brown A, et al. The use of an IV to PO clinical intervention form to improve antibiotic administration in a community based Hospital. BMJ Qual Improv Rep 2015;4:u200786. w2247.

7 Sze WT, Kong MC. Impact of printed antimicrobial stewardship recommendations on early intravenous to oral antibiotics switch practice in district hospitals. Pharm Pract 2018;16:855.

8 Teich JM, Petronzio AM, Gerner JR, et al. An information system to promote intravenous-to-oral medication conversion. Proc AMIA Symp 1999:415-9.

9 Glemaud I. Use of a physician order entry system to identify opportunities for intravenous to oral levofloxacin conversion. Am J Health Syst Pharm 2000;57(Suppl 3):S14-16.

10 Slater R. Jack Welch and the GE way: management insights and leadership secrets of the legendary CEO. New York, NY: McGrawHill, 1999.

11 Womack J, Jones D, Roos D. The machine that changed the world. New York, NY: Rawson Associates, 1990.

12 Liker J. The Toyota way: 14 management principles from the world's greatest manufacturer. New York, NY: McGraw-Hill, 2004.

13 George M. Lean six sigma for service. New York, NY: McGraw-Hill, 2003.

14 van Leijen-Zeelenberg JE, Elissen AMJ, Grube K, et al. The impact of redesigning care processes on quality of care: a systematic review. BMC Health Serv Res 2015;16:19.

15 Schweikhart SA, Dembe AE. The applicability of lean and six sigma techniques to clinical and translational research. J Investig Med 2009;57:748-55.

16 Lau BD, Pinto BL, Thiemann DR, et al. Budget impact analysis of conversion from intravenous to oral medication when clinically eligible for oral intake. Clin Ther 2011;33:1792-6. 